\title{
Óxido nítrico, GSTP-1 e p53: qual o papel desses biomarcadores nas lesões prostáticas do cão?
}

\author{
[Nitric oxide, GSTP-1 and p53: what's the role of these biomarkers \\ in dog's prostate lesions?] \\ G.B. Croce $^{1}$, M.M.P. Rodrigues ${ }^{1}$, M.B.R. Faleiro ${ }^{2}$, V.M.B.D. Moura ${ }^{3}$, R. Laufer Amorim ${ }^{4}$ \\ ${ }^{1}$ Aluna de pós-graduação - Medicina Veterinária - FMVZ-Unesp - Botucatu, SP \\ ${ }^{2}$ Aluna de pós-graduação - Escola de Veterinária - UFG - Goiânia, GO \\ ${ }^{3}$ Escola de Veterinária - UFG - Goiânia, GO \\ ${ }^{4}$ Departamento de Clínica Veterinária - FMVZ-Unesp - Botucatu, SP
}

\begin{abstract}
RESUMO
Confeccionou-se um microarranjo de tecido (TMA) com 146 amostras de lesões prostáticas caninas. Este continha 17,2\% de hiperplasia prostática benigna (HPB), 32,4\% de atrofia inflamatória proliferativa (PIA), 2,6\% de prostatite, $8,6 \%$ de focos de neoplasia intraepitelial prostática (PIN), 29,1\% de carcinomas e 9,3\% de próstatas normais. Cortes histológicos sequenciais foram feitos e utilizados para reação de imunoistoquímica com os anticorpos primários anti-p-53, anti-NOS-2 e anti-GSTP. Avaliou-se de cada core o escore de células marcadas para cada anticorpo utilizado. Os resultados foram tabulados por grupo diagnóstico e submetidos ao teste Tuckey. Os carcinomas prostáticos do cão e a PIA apresentaram maior número de amostras (41) com mais de $75 \%$ das células positivas para NOS-2, demonstrando a influência do estresse oxidativo no desenvolvimento dessas lesões. As próstatas normais e as afecções desta glândula, HPB, PIA, PIN, prostatite e carcinoma, expressaram a proteína GSTP-1, o que conferiu proteção ao tecido prostático canino a danos oxidativos. A proteína p53 estava presente em todas as amostras estudadas, incluindo o tecido prostático normal, porém as lesões prostáticas apresentaram maior número de amostras com escores mais elevados de marcação (escores três e quatro), presente em $95 \%$ dos focos de PIA e carcinoma. Concluiu-se que o aumento de expressão de óxido nítrico nas lesões prostáticas no cão e a expressão de GSTP-1 podem ter protegido o tecido prostático canino e que a expressão de p53 foi positiva e uniforme nas próstatas normais e com lesões hiperplásicas e displásicas.
\end{abstract}

Palavras-chave: cão, próstata, imunoistoquímica, óxido nítrico, GSTP-1, p53

\begin{abstract}
A tissue microarray (TMA) with 149 samples of canine prostatic lesions contained $17.2 \%$ benign prostatic hyperplasia $(\mathrm{BPH}), 32.4 \%$ proliferative inflammatory atrophy (PIA), $2.6 \%$ prostatitis, $8.6 \%$ foci prostatic intraepithelial neoplasia (PIN), 29.1\% carcinomas and 9.3\% normal prostates. Sequential histological sections were made and used for immunohistochemistry reaction with primary antibodies anti p-53, anti-NOS-2 and anti-GSTP. The score for each antibody employed was evaluated. The results were tabulated by diagnostic group and subjected to Tuckey test. Prostatic carcinomas and PIA had a higher number of samples (41) with over $75 \%$ of cells positive for NOS-2, demonstrating the influence of oxidative stress in the development of these lesions. The prostates of normal dogs, as well as the disorders of this gland (BPH, PIA, PIN, prostatitis and carcinoma), expressed GSTP-1 protein, which gives protection to the canine prostate tissue against oxidative damage. The p53 protein was present in all samples studied, including normal prostate tissue, but the prostatic lesions had a higher number of samples with higher scores (more than $50 \%$ of positive cells), in $95 \%$ of foci of PIA and carcinoma. It was found that an increased expression of NO in prostatic lesions of dogs and that the expression of GSTP-1 can protect the canine prostate tissue, which would contribute to the low frequency of prostate adenocarcinoma in this species. The expression of p53 was positive in all lesions as well as the in normal prostate.
\end{abstract}

Keywords: dog, prostate, immunohistochemistry, nitric oxide, GSTP-1, p53

Recebido em 5 de julho de 2010

Aceito em 5 de agosto de 2011

E-mail: renee@fmvz.unesp.br 


\section{INTRODUÇÃO}

O termo displasia foi introduzido por McNeal e Bostwick (1986) para designar as anormalidades das células epiteliais dos ductos e ácinos prostáticos, e foi substituído pelo termo neoplasia intraepitelial prostática (PIN), proposto por Bostwick (1995). A lesão pré-neoplásica no cão, PIN, foi descrita por Waters e Bostwick (1997) e seu diagnóstico é feito por analogia com a descrição de alterações celulares dos humanos feita por McNeal e Bostwick (1986).

Outra lesão que recentemente vem sendo estudada é a atrofia prostática. Essa afecção também é considerada precursora do adenocarcinoma prostático e ocorre associada a inflamações crônicas (de Marzo et al., 2003). A atrofia prostática pode representar uma lesão proliferativa e, como esta é acompanhada de inflamação, o termo atrofia inflamatória proliferativa (PIA) foi introduzido (de Marzo et al., 2003).

A PIA ocorre adjacente a focos de PIN de alto grau (HGPIN) e/ou câncer, e apresenta anormalidades genéticas semelhantes (Sugar, 2006). A PIA pode progredir para HGPIN e, subsequentemente, para carcinoma prostático ou evoluir diretamente para este último. Investigações sobre frequência, distribuição, estágio proliferativo e mudanças genéticas na PIA sugerem sua relação com o HGPIN e o câncer prostático em humanos (Tomas et al., 2006). Recentemente, um grupo de pesquisadores classificou as lesões prostáticas atróficas e propôs sua classificação em dois grupos: PIA e atrofia proliferativa sem inflamação (PA) (Tomas et al., 2007).

O homem e o cão são provavelmente as únicas espécies a desenvolver espontaneamente o câncer prostático, compartilhando diversas características clínicas e patológicas da doença, embora haja relatos isolados da doença em símios e felinos (Le Roy e Northrup, 2009).

$\mathrm{O}$ óxido nítrico (NO) é um radical livre inorgânico sintetizado a partir da L-arginina pela família de isoenzimas denominadas sintases de óxido nítrico (NOS). Diversos efeitos biológicos têm sido atribuídos ao NO, tais como transmissão neuronal, vasodilatação, relaxamento de músculo liso e mediador de efeitos citotóxicos de magrófagos e neutrófilos (Klotz et al., 1998). Produção anormal de NO foi demonstrada em várias condições patológicas, incluindo doenças inflamatórias e autoimunes, dano tecidual por hipóxia ou anóxia e desordens proliferativas (Grandini et al., 1999).

A proteína p-53 é considerada "guardiã" do genoma, pois, se um erro ocorrer na transcrição do DNA, ela interrompe o ciclo para que os mecanismos de reparação atuem. Se o processo falhar, acionam-se eventos apoptóticos e há destruição da célula danificada (Schmitt, 1999; Wang et al., 2009). Em células normais, a proteína $\mathrm{p}-53$, denominada tipo selvagem, tem meia-vida curta e não se acumula no tecido em concentrações detectáveis. Mutações ou deleções no gene TP--53 podem levar à produção alterada da proteína, a qual deixa de desempenhar sua função e acumula-se no tecido, podendo ser detectada por imunoistoquímica (Schmitt, 1999). A comparação da expressão de p-53 em áreas de HGPIN, HPB e adenocarcinoma prostático mostra que há diferença significativa entre sua expressão na HPB e no carcinoma. Contrariamente, quando se compara HGPIN e adenocarcinoma, a diferença não é estatisticamente significativa, estreitando a relação entre as duas lesões (Tamboli et al., 1998).

O gene GSTP-1 codifica uma enzima que atua como detoxificante carcinogênico. GSTP1 tem sido descrito como um gene "guardião", pois protege a célula ativamente de dano oxidativo do genoma mediado pelos componentes carcinogênicos (Palapattu et al., 2004; Wang et al., 2009). No epitélio prostático normal humano, a expressão de GSTP1 está geralmente confinada ao compartimento basal. Células benignas luminais podem ser induzidas a expressar GSTP1 face ao desenvolvimento do estresse oxidativo. Epitélio prostático maligno, no entanto, quase invariavelmente não expressa GSTP1 devido à ilha de hipermetilação $\mathrm{CpG}$ na região promotora do gene GSTP1 (Palapattu et al., 2004; Wang et al., 2009).

Há três isoformas de NOS, denominadas neuronal (nNOS), endotelial (eNOS) e induzida (iNOS). Neurotransmissão e vasodilatação estão associadas com nNOS, mas a citotoxicidade de macrófagos e a imunossupressão induzida nos tumores estão associadas a iNOS (Jeckins et al., 
1995). A expressão de iNOS ocorre por meio de endotoxinas e/ou citocinas, e essa enzima fornece uma liberação sustentada de óxido nítrico (Baltaci et al., 2001).

O objetivo deste estudo foi avaliar a expressão proteica de iNOS, GSTP1 e p53 pela técnica de imunoistoquímica em tecido prostático canino normal e com diferentes afecções, dentre elas HPB, PIN, PIA e carcinoma.

\section{MATERIAL E MÉTODOS}

Foram utilizadas 149 próstatas de cães provenientes do Centro de Controle de Zoonoses das prefeituras municipais de Botucatu, SP e Bauru, SP, e da Escola de Medicina Veterinária da Universidade de Goiás, Goiânia. As glândulas foram retiradas e, após todas as aferições comprimento, largura, altura e peso -, cortes de $0,5 \mathrm{~cm}$ de espessura com navalhas para micrótomo, descartáveis, foram feitos e colocados em cassetes plásticos. Em seguida, foram identificados e anotados dados de idade do animal - jovem, adulto e idoso -, raça, presença de testículos e possíveis alterações macroscópicas na próstata.

Os cassetes plásticos permaneceram no formol por 24 horas e, em seguida, foram colocados em álcool $70 \%$. Logo após, foram processados para inclusão em parafina. Foram confeccionados cortes de $3 \mu \mathrm{m}$ em micrótomo automático, colocados em estufa para desparafinizar e corados pela técnica de hematoxilina e eosina (HE). As lesões foram classificadas em PIA, de acordo com De Marzo et al. (1999), PIN, segundo Waters e Bostwick (1997), e carcinoma, de acordo com Foster e Ladds (2007).

De cada lâmina histológica confeccionada, a área das respectivas lesões foi demarcada e submetida à técnica de microarranjo de tecido (TMA), realizada no Hospital A.C. Camargo, São Paulo, SP.

Das áreas previamente definidas nos respectivos blocos de parafina foi feita biópsia (core) com o uso do equipamento Tissue Microarrayer (Beencher Instruments ${ }^{\circledR}$, Silver Spring, USA). Os cores tinham o diâmetro de $1,0 \mathrm{~mm}$, sendo introduzidos em um bloco de parafina virgem, com a distância de $0,2 \mathrm{~mm}$ entre eles (Fig 1). O bloco receptor foi seccionado em micrótomo, sendo os cortes transferidos para lâminas adesivas (Instrumedics Inc ${ }^{\circledR}$, Hackensack, NJ). A primeira delas foi corada por $\mathrm{HE}$, e os diagnósticos revistos (Fig 1). As demais permaneceram em freezer a $-20^{\circ} \mathrm{C}$, até a realização da técnica de imunoistoquímica.
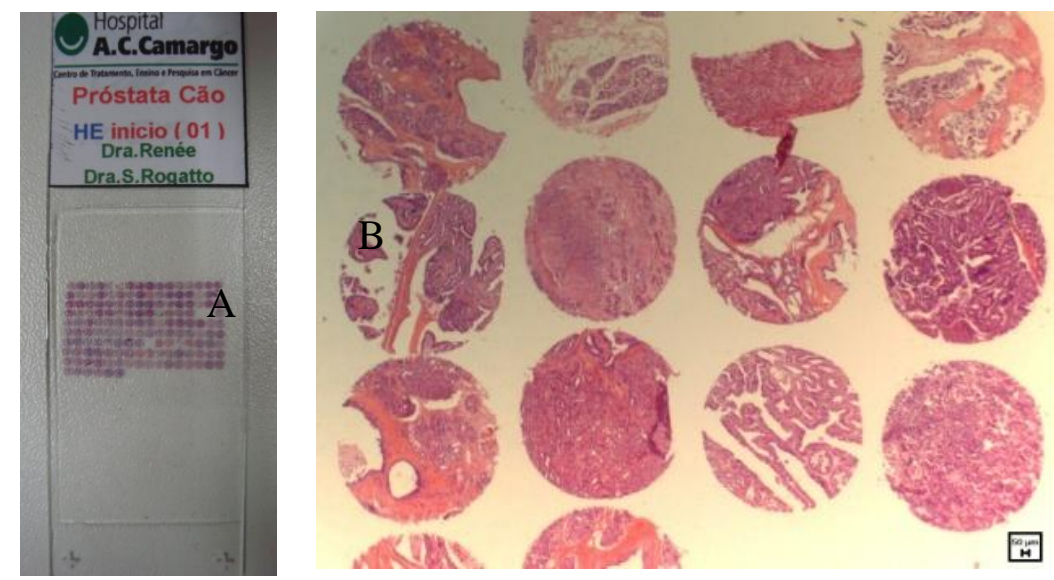

Figura 1. Lâmina de microarranjo de tecido (TMA) de próstata de cão (A). Aspecto da lâmina e (B) cores corados por HE.

Optou-se por adquirir anticorpos policlonais óxido nítrico e, após padronizações, a técnica foi realizada nas lâminas de TMA. Seguiu-se o protocolo do Laboratório de Imunoistoquímica do Serviço de Patologia da FMVZ, UNESP,
Botucatu, para os anticorpos primários óxido nítrico (iNOS-2 (N20), Ig Rabbit Santa Cruz), GSTP-1 (anti-GSTP-1 RB-050-A Glutathione STransferase, pi-Ab-1, Labvision), p53 (NCLp53-CM1, Novocastra). 
A desparafinização foi realizada com dois banhos em xilol de 30 e 20 minutos cada em temperatura ambiente, e o processo de desidratação foi realizado com passagens em álcool absoluto (três vezes de três minutos), álcool $95^{\circ}$ e álcool $85^{\circ}$. Procedeu-se à recuperação antigênica com solução de citrato 10mM, pH 6,0 pré-aquecida em câmara de pressão Pascal®. O bloqueio da peroxidase endógena foi realizado utilizando-se $92 \mathrm{~mL}$ de álcool metílico e $8 \mathrm{~mL}$ de peróxido de hidrogênio PA durante 20 minutos. Em seguida, o material foi mantido por uma hora em solução de leite Molico ${ }^{\circledR}$ diluída a 3\% em água deionizada.

Procedeu-se à incubação com o anticorpo primário na diluição de 1:100 para os anticorpos NOS-2 e GSTP-1 e 1:500 para p-53, em diluidor de anticorpos (Dako S3022) em câmara úmida por 18 horas a $4^{\circ} \mathrm{C}$ para NOS-2 e GSTP-1, e por duas horas para p-53 a $27^{\circ} \mathrm{C}$. O complexo secundário utilizado foi o Advance (Dako K4068), exceto para GSTP-1, em que foi utilizado o kit VECTASTAIN $\mathrm{ABC}^{\circledR}$ (Vector Labs), seguindo as recomendações do fabricante. As lâminas foram lavadas com solução tampão TRIS pH 7,4 entre as etapas.

Para revelação da reação, foi empregada solução pronta para uso de DAB (Dako K34466) por cinco minutos. As lâminas foram contracoradas com Hematoxilina de Harris, desidratas e montadas.

Como controle positivo das reações, utilizou-se para o anticorpo primário p53, um carcinoma de células escamosas de cão, sabidamente positivo para este anticorpo; para o GSTP-1, fígado canino, e para o NOS-2, intestino delgado de cão, ambos seguindo as recomendações do fabricante dos anticorpos primários. Os controles negativos foram feitos substituindo-se o anticorpo primário por imunoglobulina de coelho, nas mesmas condições das reações com anticorpo primário.

Para a avaliação das amostras, utilizaram-se escores em relação à porcentagem de células marcadas para os anticorpos NOS-2, GSTP-1 e p-53, sendo: 0 , sem marcação; 1 , até $25 \%$ de células marcadas; 2, 25 a $50 \%$ de células marcadas; 3, 50 a $75 \%$ e 4, 75 a $100 \%$ (adaptado de Wang et al., 2009). A leitura foi feita no foco da lesão, em objetiva de 40 vezes.

\section{RESULTADOS}

As lâminas coradas com hematoxilina e eosina foram avaliadas por três patologistas (RLA, GBC, MMPR) e classificadas de acordo com metodologia descrita (Fig. 2).

Após o estabelecimento do diagnóstico de cada amostra, escolheu-se a área mais representativa, que foi marcada com uma caneta permanente para a confecção do bloco receptor do microarranjo de tecido (TMA). Este continha $17,2 \%$ de HPB, $32,4 \%$ de PIA, 2,6\% de prostatite, $8,6 \%$ de focos de PIN, $29,1 \%$ de carcinomas e $9,3 \%$ de próstatas normais.

A Fig. 3 e as Tab. 1, 2 e 3 correspondem à imunomarcação obtida para os anticorpos estudados. Observa-se, à esquerda, a marcação nos cores e, à direita, a mesma marcação em objetiva de maior aumento.

Todas as alterações prostáticas tiveram mais de $45 \%$ das amostras classificadas no escore 4 , já as normais não passaram de 3 . O teste Tuckey, com significância de $95 \%$, revelou que o percentual de amostras de lesões prostáticas caninas com escore 4 foi significativamente diferente dos escores $1(\mathrm{P}<0,01)$ e $2(\mathrm{P}<0,05)$. As amostras de PIA e carcinoma apresentaram o maior percentual de amostras com escores mais altos (3 e 4) do que as demais lesões prostáticas estudadas e o tecido prostático normal. Já a prostatite apresentou $100 \%$ das amostras com maior imunomarcação para NOS-2 (100\%, escore 4).

Exceto a prostatite, as demais lesões e a próstata normal do cão apresentaram percentual mais alto de amostras com escore 4 para GSTP-1 (76 a $100 \%$ de células marcadas). Em uma amostra de PIA, não houve expressão desta proteína (escore zero). Considerando-se escores acima de $50 \%$ de células marcadas (escores 3 e 4), todas as lesões estudadas tinham mais de $75 \%$ das amostras nestes intervalos de imunomarcação, inclusive o tecido prostático normal. O número de amostras escore 4 foi significativamente diferente daquelas escore zero $(\mathrm{P}<0,01), 1 \quad(\mathrm{P}<0,001), 2$ $(\mathrm{P}<0,001)$ e $3 \quad(\mathrm{P}<0,01)$, pelo teste Tuckey, observado em todas as lesões. 


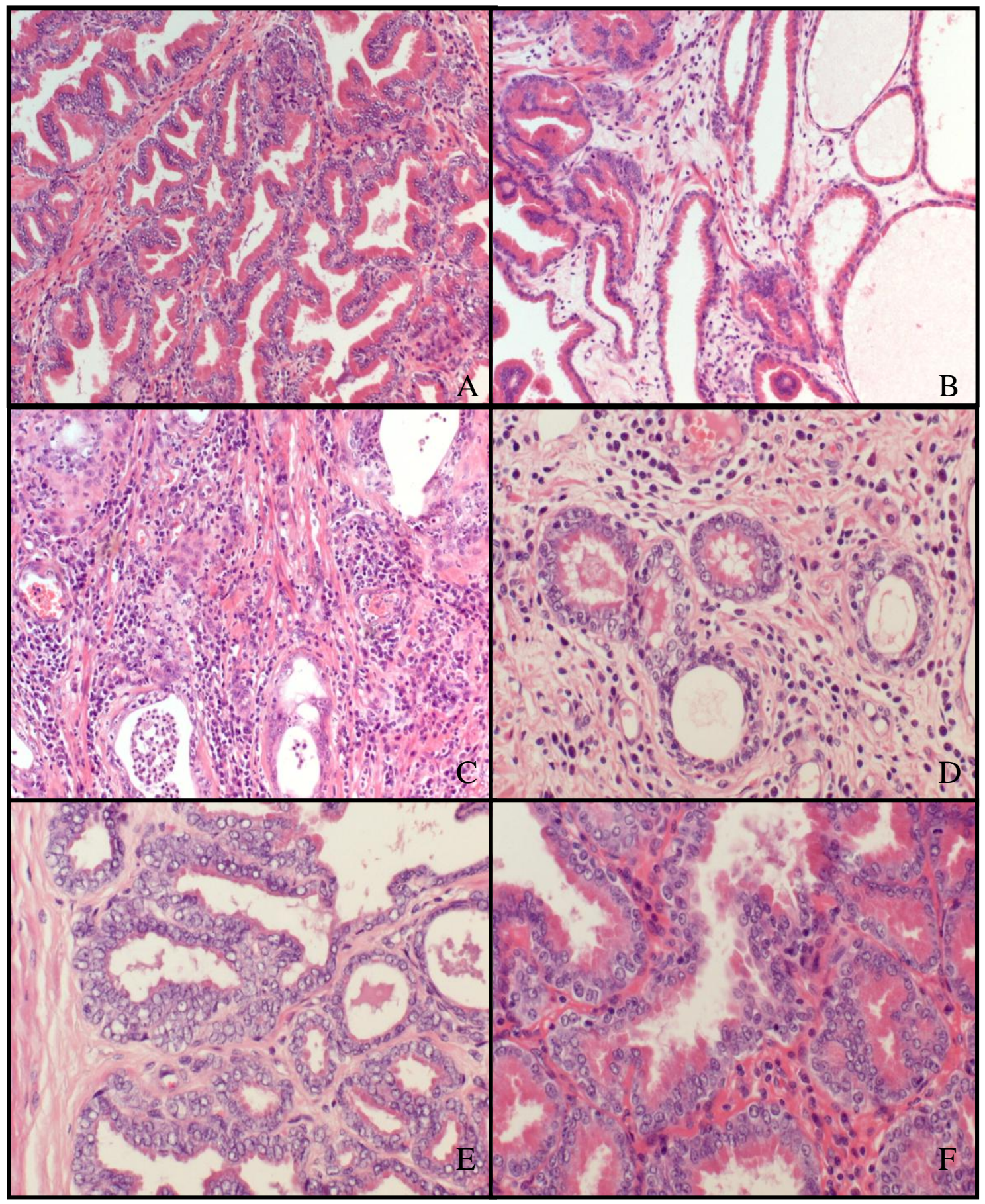

Figura 2. Próstata de cão (A) Próstata normal. Padrão epitelial e estromal característico, HE, 20x. (B) Hiperplasia prostática benigna; proliferação organizada de células epiteliais com formações císticas, HE, 20x. (C) Prostatite; intenso infiltrado inflamatório polimorfo e mononuclear difuso estromal e intracinar, HE, 20x. (D) Atrofia inflamatória proliferativa; infiltrado inflamatório mononuclear estromal e foco de atipia epitelial com atrofia, HE, 40x. (E) Neoplasia intraepitelial prostática; foco de células epiteliais que apresentam empilhamento e atipia; HE, 40x. (F) Carcinoma prostático; células epiteliais desorganizadas que apresentam atipia nuclear e nucléolos evidentes, HE, 40x. 


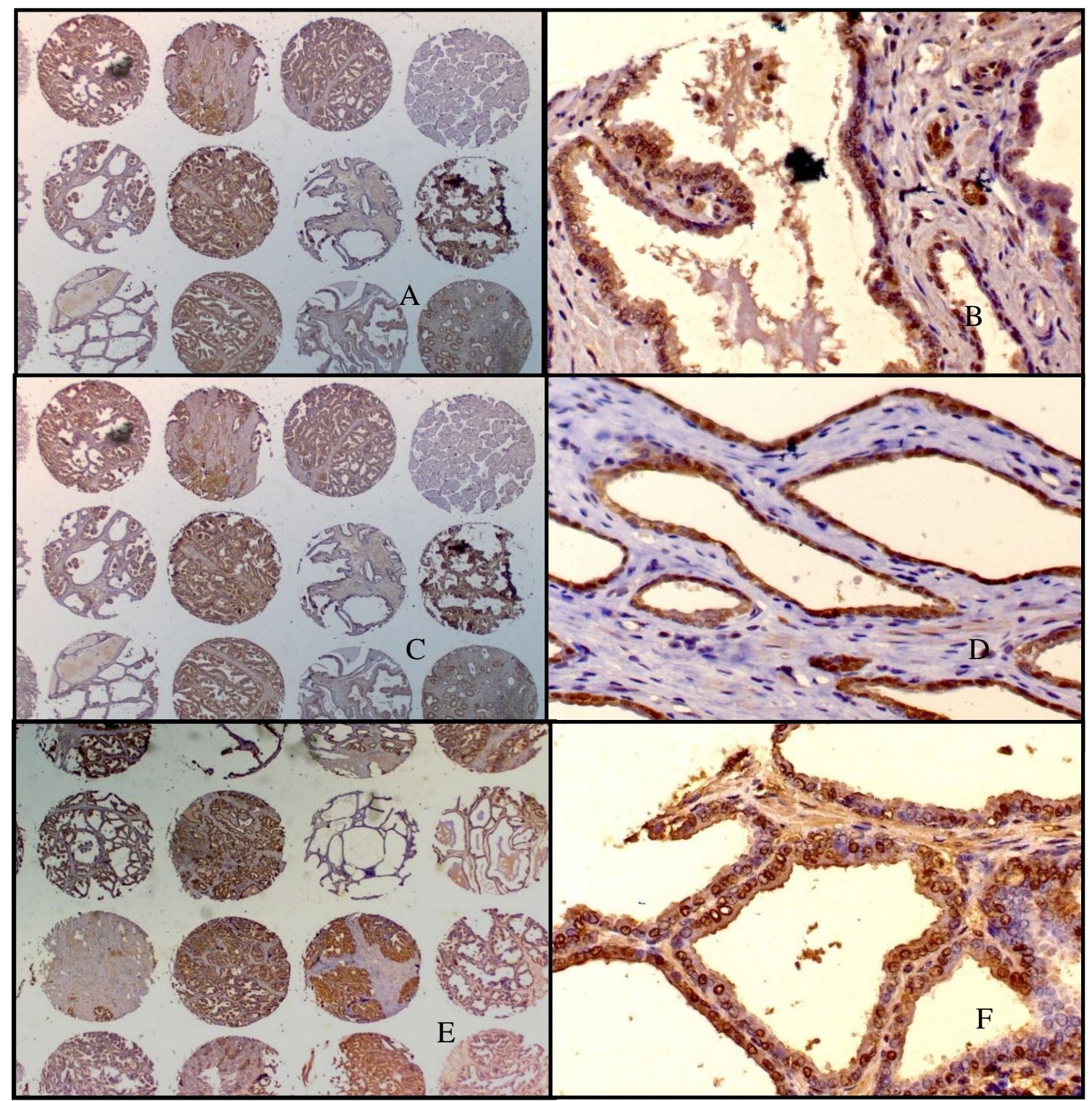

Figura 3. Próstata de cão (A). TMA imunomarcação positiva para NOS-2, objetiva de 5x. (B) Imunomarcação positiva para NOS-2, objetiva de 10x. (C) Imunomarcação positiva para GSTP-1, objetiva de 5x. (D) Imunomarcação positiva para GSTP-1, objetiva de 10x. (E) Imunomarcação positiva para p53, objetiva de 5x. (F) Imunomarcação positiva para p53, objetiva de 10x.

Tabela 1. Percentual de amostras positivas para o anticorpo primário NOS-2, de acordo com o diagnóstico histopatológico da próstata e escore de \% de células marcadas para cada lesão, em cães

\begin{tabular}{ccccccc}
\hline Diagnóstico/escore & Normal & HPB & PIA & Prostatite & PIN & Carcinoma \\
\hline Escore 0 & & & & & & \\
Escore 1 & $16,6 \%$ & $4 \%$ & & & & \\
Escore 2 & $16,6 \%$ & $12 \%$ & $4,8 \%$ & & $75,1 \%$ & $7,8 \%$ \\
Escore 3 & $66,6 \%$ & $28 \%$ & $24,3 \%$ & & $7,6 \%$ & $36,8 \%$ \\
Escore 4 & & $56 \%$ & $70,7 \%$ & $100 \%$ & $45,1 \%$ & $55,2 \%$ \\
\hline
\end{tabular}

Percentual de marcação: zero, não marcado; um, até 25\%de células marcadas por campo; dois, de 26 a 50\%; três, de 51 a $75 \%$ e quatro, mais de $76 \%$ de células marcadas por campo (adaptado de Wang et al., 2009). 
Tabela 2. Percentual de amostras positivas para o anticorpo primário GSTP-1, de acordo com o diagnóstico histopatológico da próstata e escore de \% de células marcadas para cada lesão, em cães

\begin{tabular}{ccccccc}
\hline Diagnóstico/escore & Normal & HPB & PIA & Prostatite & PIN & Carcinoma \\
\hline Escore 0 & & & $2,2 \%$ & & & \\
Escore 1 & $15,3 \%$ & & $9,1 \%$ & $25 \%$ & & $2,6 \%$ \\
Escore 2 & & $8 \%$ & $9,1 \%$ & & & $10,5 \%$ \\
Escore 3 & & $16 \%$ & & & $7,6 \%$ & $13,1 \%$ \\
Escore 4 & $86,6 \%$ & $76 \%$ & $79,5 \%$ & $75 \%$ & $92,3 \%$ & $73,6 \%$ \\
\hline
\end{tabular}

Percentual de marcação: zero, não marcado; um, até $25 \%$ de células marcadas por campo; dois, de 26 a $50 \%$; três, de 51 a $75 \%$ e quatro, mais de $76 \%$ de células marcadas por campo (adaptado de Wang et al., 2009).

Tabela 3. Percentual de células marcadas pelo anticorpo primário anti-p53 (clone CM-1) de acordo com diagnóstico histopatológico das lesões prostáticas estudadas, em cães

\begin{tabular}{ccccccc}
\hline Diagnóstico/escore & Normal & HPB & PIA & Prostatite & PIN & Carcinoma \\
\hline Escore 0 & & & & & & \\
Escore 1 & $7,6 \%$ & $3,7 \%$ & & & $14,3 \%$ & $2,6 \%$ \\
Escore 2 & $7,6 \%$ & $7,4 \%$ & $2,1 \%$ & $25 \%$ & & $2,6 \%$ \\
Escore 3 & $23,1 \%$ & $3,7 \%$ & $6,4 \%$ & $75 \%$ & $42,7 \%$ & $18,4 \%$ \\
Escore 4 & $69,2 \%$ & $85,2 \%$ & $91,5 \%$ & & $42,7 \%$ & $76,3 \%$ \\
\hline
\end{tabular}

Percentual de marcação: zero, não marcado; um, até $25 \%$ de células marcadas por campo; dois, de 26 a $50 \%$;três, de 51 a $75 \%$ e quatro, mais de $76 \%$ de células marcadas por campo (adaptado de Wang et al., 2009).

Todas as amostras avaliadas exibiram marcação para o anticorpo primário anti-p53. Os maiores números de amostras positivas no escore 4 ocorreram nos diagnósticos de HPB, PIA e carcinoma. Quando se avaliou a imunomarcação para esta proteína, superior a $50 \%$ (escores 3 e 4), observou-se que os focos de PIA e carcinomas tiveram mais de $95 \%$ das amostras nestes valores. O percentual de amostras com escore 4, independentemente da lesão histopatológica, foi diferente dos escores 1 e 2 $(\mathrm{P}<0,05)$.

\section{DISCUSSÃO}

A próstata é sítio de diversas afecções, dentre elas a neoplasia intraepitelial prostática (PIN), considerada precursora do câncer prostático (Rossignol et al., 2004). Waters e Bostwick (1997) descreveram um alto índice dessa lesão em cães, entretanto, no presente trabalho, ocorreu baixa incidência $(8,6 \%)$ semelhante ao encontrado por Rossignol et al. (2004) e Argyle (2009). Assim como descrito na literatura, registraram-se focos de PIN adjacentes aos carcinomas prostáticos, anuindo com a teoria de que a PIN seja uma lesão pré-neoplásica (Waters e Bostwick, 1997) e, como nos humanos, onde há focos de HGPIN, há carcinoma.

Na próstata normal do cão e nas lesões avaliadas, observou-se expressão proteica de NOS-2, sendo que a PIA e os carcinomas apresentaram maior número de amostras com mais de $75 \%$ de células positivas (escore 4) do que as demais amostras. Estudos de Klotz et al. (1998) e Uotila et al. (2001) indicaram que a expressão de NOS-2 é estimulada no adenocarcinoma prostático humano e que essa proteína é também expressa na PIN, como observado no presente estudo, na próstata canina. Corroborando com os resultados de Baltaci et al. (2001), que descreveram que as afecções prostáticas do homem expressam iNOS, com maior intensidade para os HGPIN e carcinoma do que para HPB, os cães apresentaram maior intensidade de marcação nos carcinomas prostáticos do que nos focos de PIN e HPB.

Todas as amostras prostáticas avaliadas apresentaram maior escore de imunomarcação (mais de $75 \%$ de todas as amostras foram escores 3 e $4->50 \%$ de células marcadas) para GSTP-1. A GSTP-1 é induzida na resposta oxidativa e deve estar aumentada nos focos de PIA, pelo infiltrado inflamatório presente (Parsons et al., 2001). Como o número de amostras positivas para NOS-2 também foi alto, infere-se que o GSTP-1 esteja aumentado em resposta ao estresse oxidativo. Resultado semelhante foi relatado na literatura humana (Wang et al., 2009). No entanto, Nakayama et al. (2003) encontraram diminuição de GSTP-1 nas áreas de PIA e propuseram que a ausência da expressão 
de GSTP-1 pode ser consequência da hipermetilação das ilhas $\mathrm{CpG}$.

Wang et al. (2009) comentaram sobre o acúmulo de p53 e a expressão aumentada de GSTP-1, que poderiam induzir a apoptose dessas células por outros mecanismos não relacionados à via do p53, como, por exemplo, a via mitocondrial, pela liberação de citocromo c. Estes resultados fazem pensar que o estudo de um biomarcador, ou um grupo pequeno deles, pode não explicar ou elucidar a progressão tumoral, em diferentes modelos. Devem-se levar em consideração as vias envolvidas e o conhecimento de que no organismo vias alternativas são responsáveis por resultados biológicos semelhantes.

O percentual de positividade para a proteína p53 foi elevado em todas as áreas. Porém, quando se avaliou a imunomarcação para esta proteína superior a $50 \%$ (escores 3 e 4), observou-se que os focos de PIA e carcinomas tiveram mais de 95\% das amostras nestes valores. O acúmulo da proteína mutante é fator de prognóstico ruim, pois a parada do ciclo celular para eventuais correções da fita de DNA e o estímulo à apoptose estarão ausentes nesta célula, por mutação do gene TP53, considerado o "guardião do genoma" (Wang et al., 2009).

Em humanos, a expressão de p53 está relacionada a índices proliferativos mais elevados no câncer prostático e na HGPIN e a um fenótipo mais agressivo no câncer (Cheng et al., 1999), e sua mutação já foi detectada em focos de PIA (Tsujimoto et al., 2002). Stricker et al. (1996) relataram que adenocarcinomas prostáticos em humanos, positivos para p53, têm maior probabilidade de progressão da doença, o que confirma com o potencial maligno dos focos de PIA, que, no presente estudo, foram reativos para essa proteína. Por outro lado, a avaliação imunoistoquímica da proteína p53 não é uma ferramenta muito precisa para correlacionar sua expressão em lesões prostáticas. Isso se deve a dois fatores: meia-vida curta da proteína, o que torna difícil sua identificação no tecido, e uma possível reação cruzada entre as formas selvagem e mutante, como demonstrado por Wang et al. (2009).

A evolução dos focos de PIA para carcinoma, ou mesmo do epitélio adjacente normal, porém com acúmulo de p53, NOS-2 e GSTP-1, associada à informação da baixa frequência de câncer de próstata na espécie canina (Rossignol et al., 2004; LeRoy e Northrup, 2009; Argyle, 2009), faz questionar se o aumento de expressão de GSTP-1 é um fator protetor e indutor da apoptose de células potencialmente malignas e se a superexpressão de NOS-2 e o acúmulo de p53 seriam indutores de proliferação celular, angiogênese, que corroboraria para o surgimento de câncer.

\section{CONCLUSÕES}

As próstatas normais de cães, bem como as afecções desta glândula, como HPB, PIA, PIN, prostatite e carcinoma, expressam a proteína GSTP-1, o que confere proteção ao tecido prostático canino a danos oxidativos. A proteína p53 está presente em todas as amostras estudadas, incluindo o tecido prostático normal, porém as lesões prostáticas apresentaram maior número de amostras com escores mais elevados de marcação.

\section{REFERÊNCIAS BIBLIOGRÁFICAS}

ARGYLE, D. Prostate cancer in dog and men: a unique opportunity to study the disease. Vet. J., v.180, p.137-138, 2009.

BALTACI, S.; ORHAN, D. Inducible nitric oxide synthase expression in benign prostatic hyperplasia, low- and high-grade prostatic intraepithelial neoplasia and prostatic carcinoma. BJU Intern., v.88, p.100-103, 2001.

BOSTWICK, D.G. High-grade prostatic intraepithelial neoplasia: the most likely precursor of prostate cancer. Cancer, v.75, p.1823-1836, 1995.

CHENG, L. p53 overexpression is associated with increased cell proliferation in patients with locally recurrent prostate carcinoma after radiation therapy. Cancer, v.85, p. 1293-99, 1999.

DE MARZO, A.M.; MARCHI, V.L.; EPSTEIN, J.I. et al. Proliferative inflammatory atrophy of the prostate: implications for carcinogenesis. Am. J. Patol., v.155, p.1985-1992, 1999.

DE MARZO, A.M. Human prostate cancer precursors and pathobiology. Urology, v.62, p.55-62, 2003.

FOSTER, R.A.; LADDS, P.W. Male genital system, In: JUBB, K.V.F.; KENNEDY, P.C.; PALMER, N. (Eds.). Pathology of domestic animals. St. Louis, MO:Elsevier Limited, 2007. p.590. 
GRANDINI, R.; REALACCI, M.; GINEPRI, A. et al. Nitric oxide synthases. In Normal and benign hyperplastic human prostate: immunohistochemistry and molecular biology. J. Pathol., v.189, p.224-229, 1999.

JENKINS, D.C. Roles of nitric oxide in tumor growth. Proc. Natl. Acad. Sci., v.92, p.4392-4396, 1995.

KLOTZ, T.; BLOCH, W.; VOLBERG, C. et al. Selective expression of inducible nitric oxide synthase in human prostate carcinoma. Cancer. v.82, p.18971903, 1998.

LE ROY, B.E.; NORTHRUP, N. Prostate cancer in dogs: comparative and clinical aspects. Vet. J., v.180, p.149-162, 2009.

McNEAL, J.E.; BOSTWICK, D.G. Intraductal dysplasia: a premalignant lesion of the prostate. Hum. Pathol., v.17, p.64-71, 1986.

NAKAYAMA, M.; BENNETT, C.J.; HICKS, J.L. et al. Hypermethylation of the human glutathione Stransferase-pi gene (GSTP1) CpG island is present in a subset of proliferative inflammatory atrophy lesions but not in normal or hyperplastic epithelium of the prostate: A detailed study using laser-capture microdissection. Am. J. Pathol., v.163, p.923-933, 2003.

PALAPATTU, G.S. Prostate carcinogenesis and inflammation: emerging insights. Carcinogenesis, v.26, p.1170-1181, 2004.

PARSONS, J.K.; NELSON, C.P.; GAGE, W.R. et al. GSTA1 expression in normal, preneoplastic, and neoplastic human prostate tissue. Prostate, v.49, p.3037, 2001.

ROSSIGNOL, A.; VILLERS, A.; MOLINIÉ, V. et al. Histologie et immunohistochimie de la prostate du chien. Validité du modèle animal pour l'étude des lesions précancéreuses. Rev. Med. Vet., v.155, p.21-26, 2004.
SCHMITH, P.J.; SKILBECK, N.; HARRISON, A.; CROCKER, J. The effect of a series of fixative on the AgNOR technique. J .Pathol., v155, p.109-12, 1999.

STRICKER, H.J.; JAY, J.K.; LINDEN, M.D. et al. Determing prognosis of clinically localized prostate cancer by immunohistochemical detection of mutant p53. Urology, v.47, p.366-369, 1996.

SUGAR, L.M. Inflammation and prostate cancer. Can. J. Urol., v.13, p.46-47, 2006.

TAMBOLI, P. Immunohistochemical expressions of retinoblastoma and p-53 tumor suppressor genes in prostatic intraepithelial neoplasia: comparasion with prostatic adenocarcinoma and benign prostate. Mod. Pathol., v.11, p. 247-252, 1998.

TOMAS, D.; KRUSLIN, B.; ROGATSCH, H. et al. Different types of atrophy in the prostate with and without adenocarcinoma. Eur. Urol., v.51, p.98-104, 2006.

TSUJIMOTO, Y.; TAKAYAMA, H.; NONOMURA, N. et al. Postatrophic hyperplasia of the prostate in Japan: Histologic and immunohistochemical features and p53 gene mutation analysis. Prostate, v.52, p.279287, 2002.

UOTILA, P.; VALVE, E.; MARTIKAINEN, P. et al. Increased expression of cycloxygenase- 2 and nitric oxide synthase- 2 in human prostate cancer. Urol. Res., v.29, p.25-28, 2001.

WANG, W.; BERGH, A.; DAMBER, J-E. Increased p53 immunoreactivity in proliferative inflammatory atrophy of prostate is retated to focal acute inflammation. Acta Pathol. Microbiol. Immunol. Scand., v.117. p.185-195, 2009.

WATERS, D.J.; BOSTWICK, D.G. The canine is a spontaneous model of intraepithelial neoplasia and prostate cancer progression. Antic. Res., v.17, p.14671470, 1997. 